\title{
Multimorbidity and cancer outcomes: a need for more research
}

This article was published in the following Dove Press journal:

Clinical Epidemiology

I November 2013

Number of times this article has been viewed

\section{Henrik Toft Sørensen Editor in Chief}

Department of Clinical Epidemiology, Aarhus University Hospital, Aarhus, Denmark
Correspondence: Henrik Toft Sørensen Department of Clinical Epidemiology, Aarhus University Hospital, Olof Palmes Allé 43-45, DK-8200, Aarhus N, Denmark

Tel +4587168215

Fax +4587167215

Email hts@dce.au.dk
Cancer incidence increases with age, and about $43 \%$ of men and $30 \%$ of women aged 65 will develop cancer in their remaining lifetimes. ${ }^{1}$ The global population is rapidly aging, and by 2030 about $70 \%$ of cancer in, for example, the US, will be diagnosed in older patients. ${ }^{2}$ Fortunately, cancer survival has improved and 5-year survival exceeds $80 \%$ for many common cancers. ${ }^{3}$ As a result of these two complementary trends, the population of cancer survivors is growing at a rate of almost $2 \%$ per year. ${ }^{4}$

As comorbidities accumulate with age, the number of patients with multimorbidity, ie, the coexistence of several chronic diseases, is increasing dramatically. ${ }^{5}$ In the US, about $80 \%$ of Medicare funds are spent on patients with four or more chronic conditions. Multimorbidity is associated with mortality, disability, low functional status, and risks of adverse drug events. ${ }^{6,7}$

Clinical and epidemiological research on cancer prognosis has mainly focused on cancers in isolation, ignoring the impact of comorbidity and co-medication on the risk of complications and mortality. Comorbidity is a medical condition that exists at the time of diagnosis of the cancer or later, but which is not a consequence of the cancer itself. ${ }^{8}$

Comorbidity is common in cancer patients, who often have adverse lifestyle factors such as alcohol use, obesity, and smoking, which cause other chronic diseases. Thus, many cancer patients have chronic disorders such as chronic obstructive pulmonary disease, acute myocardial infarction, stroke, metabolic syndrome, and osteoporosis. ${ }^{9-13}$

With the growing population of elderly patients with cancer and other chronic diseases, modern medicine will need to address multiple medical problems at once, focusing on mortality, treatment complications, quality of life, and implications for screening. ${ }^{7,14}$

In this issue of Clinical Epidemiology, comprehensive data on the impact of comorbidity and survival in cancer patients are reported. These provide very important insight into the association between multimorbidity and cancer prognoses.

These analyses underscore the need for comprehensive, well-designed observational research on comorbidity and cancer. Findings from such types of research can be translated into clinical practice through development, testing, and implementation of intervention strategies designed to minimize the impact of comorbidity and the complications of cancer and its treatment. Such research is urgently needed since many cancer patients with multimorbidity have not benefitted from the recent advances in cancer treatment. 


\section{Disclosure}

The author reports no conflict of interest in this work.

\section{References}

1. Hayat MJ, Howlader N, Reichman ME, Edwards BK. Cancer statistics, trends, and multiple primary cancer analyses from the Surveillance, Epidemiology, and End Results (SEER) Program. Oncologist. 2007; 12(1):20-37.

2. Smith BD, Smith GL, Hurria A, Hortobagyi GN, Buchholz TA. Future of cancer incidence in the United States: burdens upon an aging, changing nation. J Clin Oncol. 2009;27(17):2758-2765.

3. Jemal A, Siegel R, Xu J, Ward E. Cancer statistics, 2010. CA Cancer J Clin. 2010;60(5):277-300.

4. OCS: Office of Cancer Survivorship. National Cancer Institute 2011.

5. Wolff JL, Starfield B, Anderson G. Prevalence, expenditures, and complications of multiple chronic conditions in the elderly. Arch Intern Med. 2002;162(20):2269-2276.

6. Salive ME. Multimorbidity in older adults. Epidemiol Rev. Epub January 31, 2013.
7. Starfield B. Point: the changing nature of disease: implications for health services. Med Care. 2011;49(11):971-972.

8. Ording AG, Sørensen HT. Concepts of comorbidities, multiple morbidities, complications, and their clinical epidemiologic analogs. Clin Epidemiol. 2013;5:199-203.

9. Li M, Fitzgerald P, Rodin G. Evidence-based treatment of depression in patients with cancer. J Clin Oncol. 2012;30(11):1187-1196.

10. Elena JW, Travis LB, Simonds NI, et al. Leveraging epidemiology and clinical studies of cancer outcomes: recommendations and opportunities for translational research. J Natl Cancer Inst. 2013;105(2): 85-94.

11. Yeh ET, Bickford CL. Cardiovascular complications of cancer therapy: incidence, pathogenesis, diagnosis, and management. J Am Coll Cardiol. 2009;53(24):2231-2247.

12. Tichelli A, Socié G. Considerations for adult cancer survivors. Hematology Am Soc Hematol Educ Program. 2005:516-522.

13. Mariotto AB, Rowland JH, Ries LA, Scoppa S, Feuer EJ. Multiple cancer prevalence: a growing challenge in long-term survivorship. Cancer Epidemiol Biomarkers Prev. 2007;16(3):566-571.

14. Valderas JM, Starfield B, Sibbald B, Salisbury C, Roland M. Defining comorbidity: implications for understanding health and health services. Ann Fam Med. 2009;7(4):7357-7363.
Clinical Epidemiology

\section{Publish your work in this journal}

Clinical Epidemiology is an international, peer-reviewed, open access journal focusing on disease and drug epidemiology, identification of risk factors and screening procedures to develop optimal preventative initiatives and programs. Specific topics include: diagnosis, prognosis, treatment, screening, prevention, risk factor modification, systematic

\section{Dovepress}

reviews, risk \& safety of medical interventions, epidemiology \& biostatical methods, evaluation of guidelines, translational medicine, health policies \& economic evaluations. The manuscript management system is completely online and includes a very quick and fair peer-review system, which is all easy to use. 